\title{
PCR-ELISAs for the Detection of Campylobacter jejuni and Campylobacter coli in Poultry Samples
}

BioTechniques 30:602-610 (March 2001)

\section{B. Grennan, N.A. O'Sullivan, R. Fallon, C. Carroll, T. Smith, M. Glennon, and M. Maher National University of Ireland, Galway, Ireland}

\footnotetext{
ABSTRACT

Campylobacter species, primarily Campylobacter jejuni and Campylobacter coli, are regarded as a major cause of human gastrointestinal disease, commonly acquired by eating undercooked chicken. We describe a PCR-ELISA for the detection of Campylobacter species and the discrimination of $\mathrm{C}$. jejuni and $\mathrm{C}$. coli in poultry sam ples. The PCR assay targets the 16S/23S ribosomal RNA intergenic spacer region of Campylobacter species with DNA oligonucleotide probes designed for the specific detection of C. jejuni, C. coli, and Campylobacter species immobilized on NucleoLink $^{\mathrm{TM}}$ wells and hybridized to PCR products modified with a $5^{\prime}$ biotin moiety. The limit of detection of the PCR-ELISA was 100-300 fg (40-120 bacterial cells) for C. jejuni and $\mathrm{C}$. coli with their respective species-specific oligonucleotide probes and $10 \mathrm{fg}$ (4 bacterial cells) with the Campylobacter genus-specific probe. Testing of poultry samples, which were presumptive positive for Campylobacter following culture on the Malthus $V$ analyzer, with the PCR-ELISA determined Campylobacter to be present in $100 \%$ of samples $(\mathrm{n}=40)$ with mixed cultures of $\mathrm{C}$. jejuni/C. coli in 55\%. The PCR-ELISA when combined with culture pre-enrichment is able to detect the presence of Campylobacter and definitively identify C. jejuni and C. coli in culture-enriched poultry meat samples.
}

\section{INTRODUCTION}

Campylobacter species, primarily Campylobacter jejuni and Campylobacter coli, are regarded as a major cause of human gastrointestinal disease, com monly acquired by eating undercooked chicken (6). The percentage of Campylobacter-contaminated chicken carcasses varies, often between $50 \%-90 \%$ depending on the time of year and the number of carcasses tested. One study found that as many as $98 \%$ of chicken carcasses may be contaminated with $C$. jejuni by the time of sale (18). Campylobacters have fastidious growth requirements, and conventional detection and identification require 4-6 days (4). This has stimulated the development of more sensitive and rapid methods for identifying pathogens present in poultry. These new methods include im munomagnetic separation of pathogens, PCR amplification, pathogen-specific DNA and RNA probes, and identification of pathogen-specific ions by mass spectrometry (7). PCR-based methods (15) are particularly attractive for the detection of pathogenic microorganisms because they can be combined with microtiter, membrane, or the newly developed "real-time technologies" to enable the rapid, sensitive, and specific detection of contaminating bacteria. PCRbased detection methods have previously been described for the detection and discrimination of Campylobacter species $(2-6,8,9,12,13)$. These reports describe numerous different targets for the detection and discrimination of Campylobacter, including PCR assays based on Campylobacter flagellin
$(12,13), 16 \mathrm{~S}$ rRNA $(4,8,9), 23 \mathrm{~S}$ rRNA (3), virulence (6), and, recently, cytolethal distending toxin (CLDT) (2) genes. Some of these reports used microtiter technology for end-point detection, while many relied on standard agarose gel electrophoresis-based detection, which is time consuming, cum bersome, and not amenable to high sample throughput. We describe a PCRELISA for the detection of Campylobacter species with discrimination of C. jejuni and C. coli from poultry sam ples. The assay utilizes NucleoLink ${ }^{\mathrm{TM}}$ technology (Nalge Nunc International, Roskilde, Denmark). The NucleoLink surface is a physically modified, thermostable, optically clear resin that allows the covalent binding of $5^{\prime}$-aminated oligonucleotides (10). The PCR assay targets the $16 \mathrm{~S} / 23 \mathrm{~S}$ ribosomal RNA intergenic spacer region (Figure 1) of the Campylobacter species using genus-specific primers previously designed in this laboratory (11). DNA oligonucleotide probes designed from the sequences of $C$. jejuni, $C$. coli, and Campylobacter species (11), modified with an amine and a 12-T linker between the amine group and the speciesspecific sequence, were immobilized onto NucleoLink wells. Biotinylated PCR products amplified from Campylobacter species were alkali denatured, hybridized to the immobilized probe, and detected using streptavidin-horseradish peroxidase conjugate and the chromogenic substrate, 3,3',5,5'-tetramethylbenzidine (TMB). We describe the application of this PCR-ELISA technology for the detection of Campylobacter in poultry meat samples. 


\section{MATERIALS AND METHODS}

\section{Bacterial Strains}

The bacterial strains listed in Tables 1 and 2 were obtained from the National Collection of Typed Cultures (NCTC), Public Health Laboratory Service (PHLS) Central Public Health Laboratory, London, UK.

\section{Primers and Probes}

All primers and oligonucleotide probes were previously designed in this laboratory $(1,11)$ and were purchased from Genosys Biotechnologies (Cambridgeshire, UK). All primers were biotinylated, and the DNA oligonucleotide probes for Campylobacter genus, $C$. jejuni, and $C$. coli species detection were modified with a $5^{\prime}$ amine and 12 $\mathrm{T}$ linker between the amine group and the sequence-specific oligonucleotide. This linker distanced the probe from the microplate surface as recommended by Nalge Nunc International (Table 3 ).

\section{Culture Conditions}

Campylobacter type strains (Table 1) for DNA isolation were grown on Campylobacter Blood-Free Agar (Ox- oid, Hampshire, UK) at $37^{\circ} \mathrm{C}$ in a $3.5-\mathrm{L}$ anaerobic jar (Oxoid) with Campylobacter gas packs (Oxoid) and palladium catalyst for 48 h. Campylobacter upsaliensis strains were grown under the same conditions for $72 \mathrm{~h}$. DNA was extracted using the AGTC Genomic DNA Purification Kit (Edge Biosystems, Gaitherburg, MD, USA) with modifications (11). All non-Campylobacter strains used in this study were grown on LB medium (16) overnight (16 h) at $37^{\circ} \mathrm{C}$. For the purpose of PCR amplification, a single colony was removed from a plate, emulsified in $100 \mu \mathrm{L}$ water, and heated to $95^{\circ} \mathrm{C}$ for $20 \mathrm{~min}$. Five microliters were added to the PCR.

\section{PCR Assay}

PCR was performed in a final volume of $100 \mu \mathrm{L}$. Each reaction contained 0.25 $\mathrm{mM}$ uracil-deoxynucleotidetriphosphate (dU:dNTP) at a ratio of 2:1 dUTP:dTTP (Roche Molecular Biochemicals, East Sussex, UK), 2 mM MgCl 2 (Life Technologies, Paisley, UK), $1 \times$ reaction buffer (Life Technologies), $100 \mathrm{ng}$ (12.5 pmol) CAMP1F-B and B1-B primers modified with $5^{\prime}$ biotin, $1 \mathrm{U}$ uracil-Nglycosolase (UNG) (Roche Molecular Biochemicals), 0.5 U Taq DNA polymerase (Life Technologies), and $5 \mu \mathrm{L}$ target material. The target material was purified Campylobacter DNA, boiled enriched Malthus media, or boiled emulsified bacterial colony and was added to the PCR and made up to a final volume of $100 \mu \mathrm{L}$ with Nuclease-free water (Sigma-Aldrich, Dorset, UK). PCR cycling conditions for the CAMP1F-B/B1$\mathrm{B}$ primer set (for the amplification of Campylobacter strains) using the Touchdown $^{\mathrm{TM}}$ thermocycler (Hybaid, Teddington, UK) were $37^{\circ} \mathrm{C}$ for $10 \mathrm{~min}$, followed by 35 cycles of $95^{\circ} \mathrm{C}$ for $30 \mathrm{~s}$, $53^{\circ} \mathrm{C}$ for $40 \mathrm{~s}$, and $72^{\circ} \mathrm{C}$ for $40 \mathrm{~s}$. PCR cycling conditions for the A1-B/B1-B (1) primer set (for the amplification of non-Campylobacter strains) using the Touchdown thermocycler were $37^{\circ} \mathrm{C}$ for $10 \mathrm{~min}$, followed by 35 cycles of $95^{\circ} \mathrm{C}$ for $30 \mathrm{~s}, 53^{\circ} \mathrm{C}$ for $40 \mathrm{~s}$, and $72^{\circ} \mathrm{C}$ for 40 s. A no-template (distilled water) negative control and a positive control of purified Campylobacter DNA were included in each PCR run. Ten microliters of PCR product were run on a $1.8 \%$ agarose gel in $1 \times$ TBE buffer.

\section{Microplate Detection}

The solid phase capture oligonucleotides, CJEJ7 specific for $C$. jejuni, CCOL2 specific for C. coli, and CAMP4 specific for Campylobacter

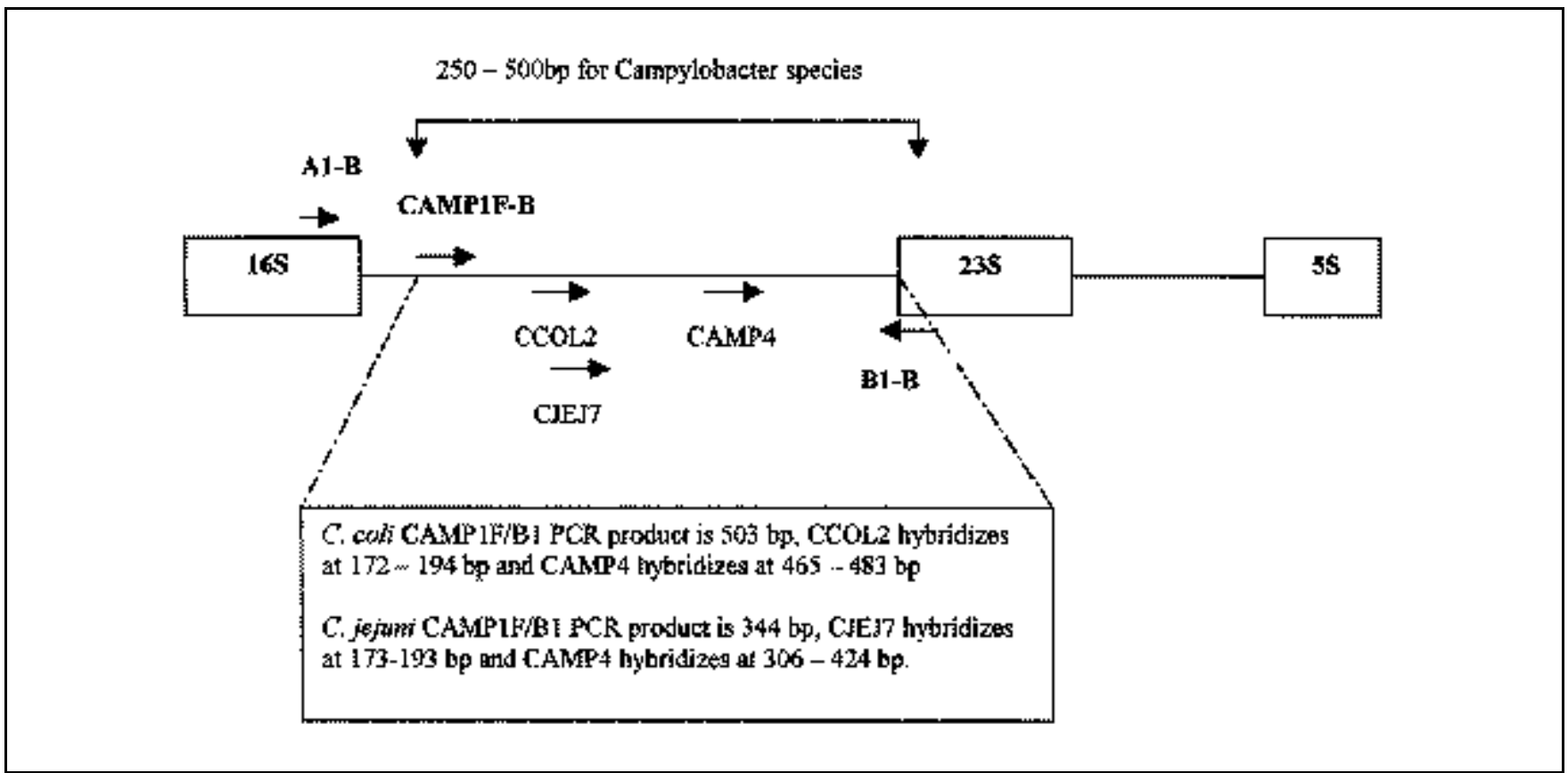

Figure 1. Schematic representation of the ribosomal RNA operon with the universal PCR primers A1-B/B1-B, Campylobacter-specific primer CAMP1FB, the Campylobacter species-specific probes CJEJ7, CCOL2, and the Campylobacter genus-specific oligonucleotide probe CAMP4. 
genus detection were $5^{\prime}$ aminated with a linker of 12 Ts between the $5^{\prime}$ end of the oligonucleotide and the amine group. A freshly made coating mixture consisting of $100 \mathrm{nM}$ oligonucleotide, $10 \mathrm{mM}$ EDAC (1-ethyl-3-(3-dimethylaminopropyl)-carbodiimide), and 10 $\mathrm{mM}$ 1-methyl-imidazole ( $\mathrm{pH}$ 7.0) was prepared. To each NucleoLink well, $100 \mu \mathrm{L}$ of this solution was added, giving a final concentration of $10 \mathrm{pmol} 5^{\prime}$ aminated oligonucleotide in each well. Some wells were coated with Posdet (Table 3) at a concentration of $10 \mathrm{pmol}$. The Posdet oligonucleotide, consisting of a random sequence with a $5^{\prime}$ amine and a $3^{\prime}$ biotin, was immobilized on a separate set of wells to serve as a positive control for the detection stage of the assay. The NucleoLink wells were sealed and incubated overnight at $50^{\circ} \mathrm{C}$. Following coating with the various oligonucleotide probes overnight, the wells were washed three times, soaked for $5 \mathrm{~min}$, and washed again three times in $100 \mathrm{mM}$ Tris- $\mathrm{HCl}$ (pH 7.5), $150 \mathrm{mM}$ $\mathrm{NaCl}$, and $0.1 \%$ Tween ${ }^{\circledR} 20$ at room temperature. To remove salt residue, the NucleoLink wells were washed three times, soaked for $5 \mathrm{~min}$, and washed three times with deionized sterile water. The coated NucleoLink wells were stored at $4^{\circ} \mathrm{C}$ in a dry, sealed plastic bag until required but were not stored for longer than 10 months. Following PCR amplification, $10 \mu \mathrm{L}$ PCR product was added to the NucleoLink wells containing genus-specific or appropriate species-specific immobilized capture oligonucleotide probe, denatured by the addition of $10 \mu \mathrm{L} 1 \mathrm{M}$ $\mathrm{NaOH}$ with $0.5 \mathrm{mg} / \mathrm{mL}$ thymol blue, and incubated at room temperature for 10 min. Eighty microliters of $6.25 \times$ standard saline citrate (SSC), $0.625 \%$ blocking reagent (Roche Molecular Biochemicals), $0.125 \%$ Tween 20, and $0.5 \mathrm{M} \mathrm{NaH}_{2} \mathrm{PO}_{4}$ adjusted to $\mathrm{pH} 6.5$ with $\mathrm{NaOH}$ were added to each well and incubated at $50^{\circ} \mathrm{C}$ for $2 \mathrm{~h}$. The wells were washed three times at room temperature with $0.5 \times \mathrm{SSC}$ and $0.1 \%$ Tween 20 , soaked for $15 \mathrm{~min}$ at $50^{\circ} \mathrm{C}$, and washed again three times at room temperature. To detect the immobilized DNA probe-PCR hybrid, $100 \mu \mathrm{L}$ of a 1:5000 dilution of the streptavidinhorseradish peroxidase conjugate (Life Technologies) in $100 \mathrm{mM}$ Tris- $\mathrm{HCl}$

Table 1. Campylobacter Species Analyzed in This Study

\begin{tabular}{|ll|}
\hline Campylobacter Species & \multicolumn{1}{c|}{ Source } \\
\hline C. jejuni & NCTC 8116 \\
C. jejuni & NCTC 11351 Biotype I \\
C. jejuni & NCTC 11168 Biotype I \\
C. jejuni & NCTC 12106 Biotype II \\
C. jejuni & NCTC 12275 Biotype III \\
C. jejuni & NCTC 12109 Biotype IV \\
C. jejuni & Penner 0:19 \\
C. jejuni & Penner 0:4 \\
C. jejuni & Penner 0:6 \\
C. jejuni & Penner 0:3 \\
C. coli & NCTC 11366 \\
C. coli & NCTC 11353 \\
C. coli & NCTC 12110 Biotype I \\
C. coli & NCTC 12143 Biotype II \\
C. fetus & NCTC 10842 \\
C. lari & NCTC 11352 \\
C. lari & NCTC 11458 \\
C. lari & NCTC 12144 \\
C. upsaliensis & NCTC 11840 \\
\hline
\end{tabular}

Table 2. Non-Campylobacter Strains Analyzed in This Study

\begin{tabular}{|ll|}
\hline Non-Campylobacter Strains & Source \\
\hline Staphylococcus epidermidis & NCTC 11047 \\
Proteus rettgeri & NCTC 7475 \\
Proteus mirabilis & NCTC 10975 \\
Lactococcus lactis & NCTC 0662 \\
Bacillus cereus & NCTC 7476 \\
Bacillus subtilis & NCTC 10400 \\
Klebsiella aerogenes & NCTC 9528 \\
Aeromonas hydrophila & NCTC 8049 \\
Enterococcus faecalis & NCTC 775 \\
Escherichia coli & NCTC 10418 \\
Listeria monocytogenes & NCTC 11994 \\
Salmonella poona & NCTC 4840 \\
Pantonea agglomerans & NCTC 9381 \\
Pseudomonas aeruginosa & NCTC 10332 \\
Salmonella enteritidis & NCTC 4444 \\
Salmonella typhimurium & NCTC 0074 \\
\hline
\end{tabular}

(pH 7.5), $150 \mathrm{mM} \mathrm{NaCl}, 0.1 \%$ Tween 20 , and $0.5 \%$ blocking reagent were added to each well and incubated for 1 $\mathrm{h}$ at room temperature. The strips were washed three times, soaked for $5 \mathrm{~min}$, and washed three times with $100 \mathrm{mM}$ Tris- $\mathrm{HCl}$ (pH 7.5), $150 \mathrm{mM} \mathrm{NaCl}$, and
$0.1 \%$ Tween 20 at room temperature. One hundred microliters of TMB were added to each well, sealed, and incubated for approximately $30 \mathrm{~min}$ at room temperature. To stop the reaction, 100 $\mu \mathrm{L} 1 \mathrm{M} \mathrm{H}_{2} \mathrm{~S} \mathrm{O}_{4}$ were added, and the absorbance was measured at $450 \mathrm{~nm}$ in an 


\section{Research Report}

EAR 400AT-SLT (SLT-Lab-Instruments, Salzburg, Austria) plate reader.

\section{Analysis of Broiler Samples}

Samples were collected from a total of 40 broiler chickens from four different points along the processing line in a chicken processing plant. The presumptive presence of Campylobacter was determined by using the Malthus $\mathrm{V}^{\mathrm{M}}$ analyzer (Malthus Instruments, West Sussex, UK) and by conventional plate count method on $25 \mathrm{~g}$ chicken neck skin flap samples. Aliquots $(100 \mu \mathrm{L})$ of liquid media from samples identified as presumptive/suspect positive for Campylobacter on the Malthus $\mathrm{V}$ analyzer were spread-plated on Campylobacterselective agar. Three colonies were selected at random from each plate for biotyping with the API-Campy strips (BioMerieux, Marcy-l'Etolie, France). PCR was performed directly on the presumptive positive Malthus Campylobacter-selective liquid media by heating $100 \mu \mathrm{L}$ liquid medium to $95^{\circ} \mathrm{C}$ for $20 \mathrm{~min}$. The bacterial cell lysate $(5 \mu \mathrm{L})$ was added to the PCR mixture and analyzed by PCR-ELISA.

\section{RESULTS}

To determine the detection limit of the $C$. jejuni- and $C$. coli-specific oligonucleotide probes and Campylobacter genus oligonucleotide probes in PCRELISA format, serial dilutions of purified $C$. jejuni and $C$. coli DNA ranging from $1 \mathrm{ng}$ to $10 \mathrm{fg}$ were PCR-amplified with CAMP1F-B/B1-B primer set (344 bp for $C$. jejuni, 503 bp for $C$. coli). Ten microliters of each PCR product were hybridized to NucleoLink wells with immobilized CJEJ7, CCOL2, or CAMP4 probes as described. The cutoff value for the detection level was set at the mean of the background signal plus three standard deviations $(\bar{x} \pm 3$ $\mathrm{SD})$. The mean absorbance value on $\mathrm{Nu}$ cleoLink strips for background signals, as determined by hybridizing $10 \mu \mathrm{L}$ PCR to which no template DNA was added, to NucleoLink wells containing CJEJ7, CCOL2, or CAMP4 oligonucleotide probes, were $0.104 \pm 0.02$ for CCOL2, $0.2 \pm 0.01$ for CJEJ7, and $0.029 \pm 0.005$ for CAMP4. From these cut-off values, a positive value for each oligonucleotide probe was determined as A values greater than $0.165,0.23$, and 0.045 positive for CCOL2, CJEJ7, and

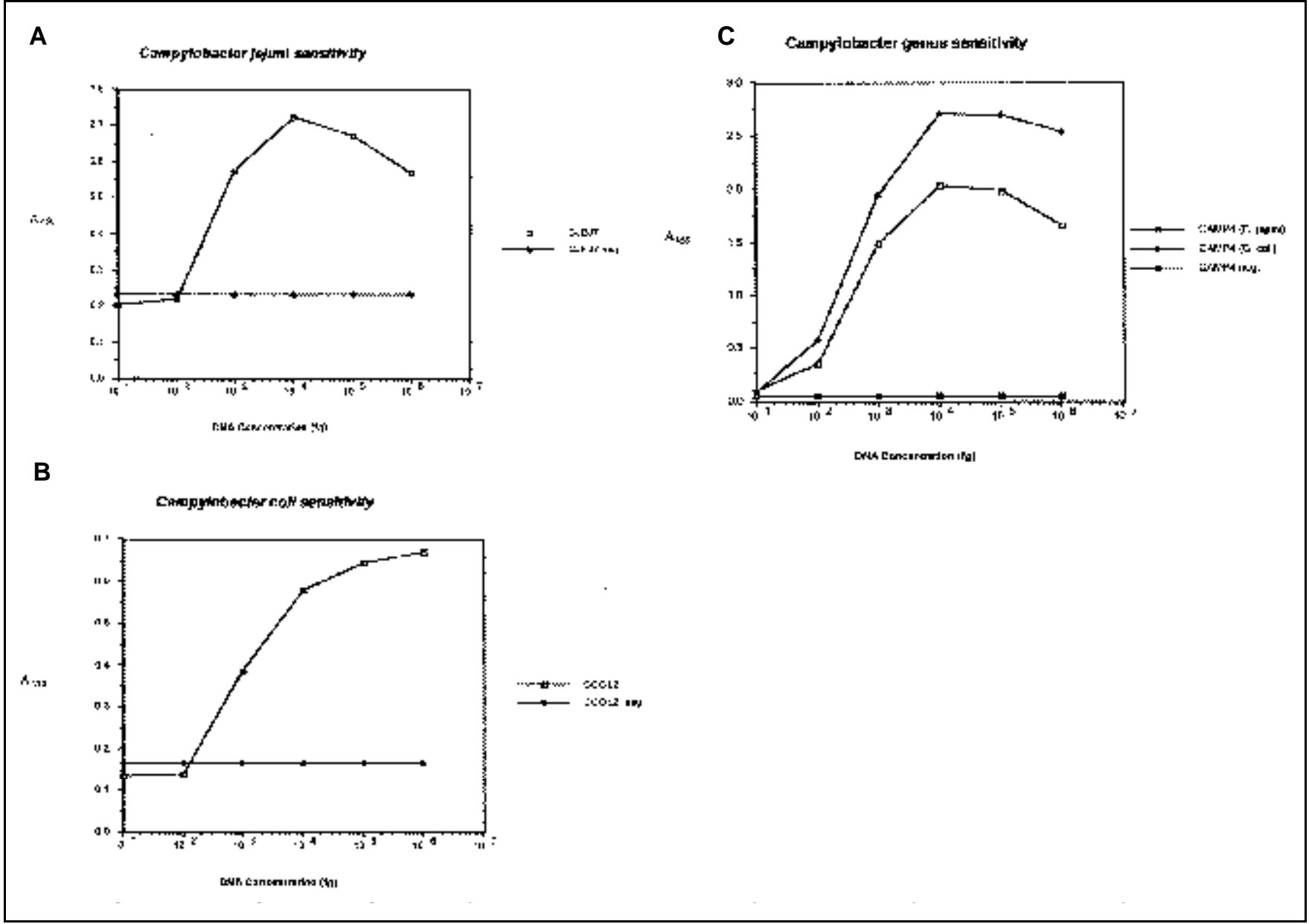

Figure 2. Sensitivity of detection of biotinylated amplified PCR products of $1 \mathrm{ng}$ to $10 \mathrm{fg}$ purified Campylobacter DNA with the probes CJEJ7 (A), CCOL2 (B), and CAMP4 (C) immobilized on NucleoLink wells. The detection limits of A, B, and C are indicated by the horizontal lines. (A) Detection of C. jejuni with CJEJ7 species-specific oligonucleotide probe. (B) Detection of $C$. coli with CCOL2 species-specific oligonucleotide probe. (C) Detection of $C$. jejuni and C. coli DNA with the Campylobacter genus-specific CAMP4 oligonucleotide probe. 


\section{Research Report}

CAMP4, respectively (Figure 2). The background for the species-specific probes, CJEJ7 and CCOL2, was tenfold higher than the genus-specific probe, CAMP4. These cut values gave a detection limit for CJEJ7 and CCOL2 probes in the PCR-ELISA of 100-300 fg (40-120 bacterial cells) for $C$. jejuni and $C$. coli DNA, respectively, while the CAMP4 genus-specific probe had a detection limit of $10 \mathrm{fg}$ (4 bacterial cells) for both $C$. jejuni and $C$. coli DNA (Figure 2). The detection limits of $C$. jejuniand $C$. coli-purified DNA, following PCR amplification, on a $1.8 \%$ agarose gel were $1 \mathrm{pg}$ for $C$. jejuni DNA and 10 $\mathrm{pg}$ for $C$. coli DNA. The sensitivities of detection of the CJEJ7, CCOL2, and CAMP4 probes were evaluated in Southern blot hybridization (17) assays. CAMP4 and CJEJ7 had a detection lim it of $100 \mathrm{fg}$ for $C$. jejuni DNA, while CAMP4 and CCOL2 had a detection limit of $100 \mathrm{fg}$ to $1 \mathrm{pg}$ with $C$. coli DNA (data not shown).

The specificity of CAMP4 for the detection of members of the Campylobacter genus and the species-specific detection of CJEJ7 and CCOL2 DNA probes was evaluated against a panel of Campylobacter strains, two $C$. jejuni (NCTC 8116 and 11351), one $C$. coli (NCTC 11366), one Campylobacter fetus (NCTC 10842), three Campylobacter lari (NCTC 11352, 11458, and 12144) and one Campylobacter upsaliensis (NCTC 11840) (Table 1) in the microplate format and previously by Southern blot and DNA probe colorimetric membrane hybridization (11). In this study, the CJEJ7, CCOL2, and CAMP4 probes were also evaluated against additional $C$. jejuni (NCTC $11168,12106,12109,12275$, and Penner serotypes $0: 19,0: 4,0: 3,0: 6)$ and $C$. coli (NCTC 11353, 12110, and 12143) strains, representing the various Campylobacter biotypes, by Southern blot hybridization analysis (data not shown). The CAMP4 binds to all mem bers of the Campylobacter genus, while CJEJ7 binds specifically to $C$. jejuni and CCOL2 to $C$. coli. The nonCampylobacter strains used to test the specificity of the CJEJ7, CCOL2, and CAMP4 probes are listed in Table 2. PCR amplification of $5 \mu \mathrm{L}$ emulsified colony heated to $95^{\circ} \mathrm{C}$ for $20 \mathrm{~min}$ from each of these species was performed

Table 3. Sequences and Descriptions of the Oligonucleotides Used in This Study

\begin{tabular}{|c|c|c|c|}
\hline $\begin{array}{l}\text { Oligo- } \\
\text { nucleotide }\end{array}$ & Sequence $\left(5^{\prime} \rightarrow 3^{\prime}\right)$ & $\mathbf{T}_{\mathrm{m}}\left({ }^{\circ} \mathbf{C}\right)$ & Modification \\
\hline aA1-B & BIO-AGTCGTAACAAGGTAGCCG- & 58.0 & Biotinylated \\
\hline aB1-B & BIO-CYRYTGCCAAGGCATCCACC- & 68.6 & Biotinylated \\
\hline aCAMP1F-B & BIO-GTTAAGAGTCACAAGCAAGT- & 53.4 & Biotinylated \\
\hline aCAMP4 & AMI-GGTAAGCTACTAAGAGCG- & 51.7 & $\begin{array}{c}\text { Aminated/12 } \\
\text { Thymidine }\end{array}$ \\
\hline aCJEJ7 & AMI-GCTTAGTTGAGACTAAATCA- & 51.1 & $\begin{array}{c}\text { Aminated/12 } \\
\text { Thymidine }\end{array}$ \\
\hline aCCOL2 & AMI-GACTTAGTTTAGATATITITAG- & 45.9 & $\begin{array}{c}\text { Aminated/12 } \\
\text { Thymidine }\end{array}$ \\
\hline POSDET & AMI-NNNNNNNNNNNN-BIO & 32.0 & $\begin{array}{l}\text { Aminated/ } \\
\text { Biotinylated }\end{array}$ \\
\hline
\end{tabular}

with A1-B/B1-B primer set, and PCR products of the appropriate size were generated for all species (300-700 bp). PCR amplification with the CAMP1FB/B1-B primer set failed to yield PCR products for any of the species, while hybridization of $10 \mu \mathrm{L}$ A1-B/B1-B $\mathrm{PCR}$ products from these organisms to CJEJ7, CCOL2, and CAMP4 probes in the PCR-ELISA did not yield positive A readings. This was consistent with the results we obtained following Southern blot analysis and the DNA probe colorimetric membrane hybridization analysis (11) of these PCR products with each of the oligonucleotide probes.

PCR amplification with the primer set CAMP1F-B/B1-B was performed on $5 \mu \mathrm{L}$ Malthus liquid from 40 chicken neck skin flap samples that were cultured for $30 \mathrm{~h}$ and yielded presumptive positive results on the Malthus analyzer. All of the samples analyzed were positive with the Campylobacter genus-specific probe (CAMP4), 40 were $C$. jejuni positive with the CJEJ7 probe, and 22 gave positive hybridization signals with CCOL2, which is specific for $C$. coli. The presence of mixed PCR products for $C$. jejuni and $C$. coli corresponding to a mixed culture of the organisms was also confirmed by gel electrophoresis and Southern blot analysis with digoxigenin (DIG)-labeled (Roche Molecular Biochemicals) CJEJ7 and CCOL2 probes (data not shown). Aliquots (100 $\mu \mathrm{L}$ ) of liquid media from samples identified as presumptive/suspect positive for Campylobacter on the Malthus V analyzer were also spread-plated on Cam pylobacter-selective agar. Three colonies were selected at random from each plate for biotyping with the API-Campy strips. The API-Campy strips clearly identified most colonies as $C$. jejuni, some as $C$. coli, and in $14 \%$ of the colonies randomly selected, the API-Campy strips yielded unacceptable profiles for designation as Campylobacter species.

\section{DISCUSSION}

We report on the development of PCR-ELISAs for Campylobacter detection with discrimination of $C$. jejuni and $C$. coli and describe the application of the technology to the detection of Campylobacter in poultry meat samples.

The PCR assay targets amplification of $16 \mathrm{~S} / 23 \mathrm{~S}$ rRNA intergenic spacer region in Campylobacter using a CAMP1F-B/B1-B primer set specific for amplification of members of the Campylobacter genus. This PCR amplification assay was combined with genus- and species-specific probes for $C$. jejuni and $C$. coli formulated as an ELISA using NucleoLink technology. The sensitivity study showed a detection limit for both $C$. jejuni- and $C$. coli-purified DNA of 100-300 fg with the species-specific probes CJEJ7 and 
CCOL2 and $10 \mathrm{fg}$ with the genus-specific probe CAMP4. For other detection formats, Southern blot hybridization analysis and DNA probe membrane-based colorimetric detection, CAMP4 and CJEJ7 DNA probes had the same detection limits for $C$. jejuni DNA, while CAMP4 and CCOL2 had the same detection limits for $C$. coli DNA. In the microplate detection format, we consistently achieved a tenfold lower detection limit with CAMP4 for $C$. coli and $C$. jejuni DNA. The tenfold lower sensitivity that was achieved with CAMP4 in the microplate ELISA is a direct reflection of the tenfold lower background signal seen with this probe by comparison with background signals for CJEJ7 and CCOL2 in this format. The NucleoLink surface has been previously used to detect human papilloma virus, Salmonella typhimurium DNA prepared from boiled bacterial cells, RNA from PYV potato virus following RT-PCR, DNA from $\lambda$-bacteriophage, and DNA from the fungus Phytophtora fragariae (10). Compared with gel electrophoresis, the detection limit for all the systems was 10-100fold lower and comparable with the detection limits described in our assay.

Specificity studies showed that the primer set (CAMP1F-B/B1-B) amplified only members of the Campylobacter genus (11). The specificities of the Campylobacter probes CJEJ7 specific for $C$. jejuni, CCOL2 specific for $C$. coli, and CAMP4 specific for members of the Campylobacter genus were evaluated on the NucleoLink strips and previously by Southern blot analysis and DNA probe colorimetric membrane assay (11). The oligonucleotide probes did not cross-react with $16 \mathrm{~S} / 23 \mathrm{~S}$ rRNA PCR products from other non-Campylobacter species.

Evaluation of poultry samples with the PCR-ELISA, which were presumptive positive for Campylobacter follow ing culture on the Malthus $\mathrm{V}$ analyzer, confirmed the presence of Campylobacter in all samples and demonstrated the presence of mixed cultures of $C$. jejuni and $C$. coli in 22 out of 40 samples. In a previous study, 101 broiler chicken samples were tested (11), and 55 out of the 101 samples were found to be PCR/DNA probe positive for $C$. jeju$n i$ and $C$. coli $(54.4 \%)$. In the current study, the 40 broiler chicken samples analyzed following Malthus culture represent a random subset of the above 101 samples. PCR amplification with the CAMP 1-F/BI-B primer pair was performed on different aliquots (100 $\mu \mathrm{L}$ ) of Malthus-enriched culture media by the principle authors in both studies. Post-PCR detection and identification of the PCR products were performed using the same DNA probes, CAMP4, CJEJ7, and CCOL2, in the two different detection formats. A complete correlation in the relative percentage of mixed cultures and the samples from which they were derived was achieved in both studies. Analytical profile index (API) analysis on some of the colonies selected following spread-plating of an aliquot of the Malthus-enriched media yielded inconclusive results for $14 \%$ of the colonies tested. Hydrolysis of hippurate in the API strips is frequently used to distinguish $C$. jejuni from $C$. coli, but the test is not always reliable (14). The PCR-ELISA detected the presence of Campylobacter and identified the Campylobacter species present in $100 \%$ of the samples analyzed. The ability to differentiate $C$. jejuni from $C$. coli is particularly important because erythromycin-based treatments are not adequate if the enteritis is caused by $C$. coli, which may be more likely to be resistant to this antibiotic. Rapid assays capable of discriminating these two species would be particularly useful in outbreak situations in which large num bers of specimens need to be handled quickly so that the appropriate therapy can be instituted (5).

PCR assays based on Campylobacter flagellin $(12,13), 16 \mathrm{~S}$ rRNA $(4,9)$, 23S rRNA (3), and, recently, CLDT (2) genes have previously been described for the detection of Campylobacter. A number of these assays rely on gelbased analysis $(2,3,4)$ Southern blot with nonradioactive DIG (5) or enhanced chemiluminescence-labeled (12) probes to detect PCR products and increase the sensitivities of the assays. These methods can be cumbersome and restrict the number of samples that may be speedily processed. An earlier study has described a PCR assay combined with microplate hybridization for the detection and discrimination of C. jeju$n i$ and $C$. coli in chicken fecal samples 
both before and after selective enrichment (13). The detection limits of four Campylobacter cells with the PCRELISA in this study using the genusspecific CAMP4 oligonucleotide probe is comparable to $1-20$ cells detected in a previous PCR-ELISA (13). It is also comparable to PCR assay sensitivities of 100 cells (6) and to the PCR assay sensitivities of 5-50 cfu achieved in a study (9) that describes PCR/DNA probes based on a $16 \mathrm{~S}$ ribosomal RNA sequence for the detection of Campylobacter in stool specimens. Other research groups report sensitivities of 1-5 cells with a PCR assay targeted to the 23S rRNA gene (3) and a PCR/DNA probe for the flaA gene with a detection limit of four cells.

The PCR-ELISA described in this study is very simple and can be performed within one day following culture-based enrichment of poultry samples. This represents significant timesaving over conventional microbiological methods and also offers the ad- vantage of being able to definitively identify $C$. jejuni and C. coli and discriminate between the organisms in mixed cultures.

\section{ACKNOWLEDGMENTS}

The authors would like to thank Paul White for collection of the broiler chicken samples used in this study and Henrik Rasmussen, Janne Knudsen, and Tina Kristensen at Nunc A/S for technical support. This work was supported by the Department of Agriculture Non-Commissioned Food Research Programme.

\section{REFERENCES}

1.Barry, T., G. Colleran, M. Glennon, L.K. Dunican, and F. Gannon. 1991. The 16S/23S ribosomal spacer region as a target for DNA probes to identify eubacteria. PCR Methods Appl. 1:51-56.

2.Eyigor, A., K.A. Dawson, B.E. Langlois, and C.L. Pickett. 1999. Detection of cytolethal distending toxin activity and $c d t$ genes in Campylobacter spp. isolated from chicken carcasses. Appl. Environ. Microbiol. 65:1501-1505.

3.Fermer, C. and E.O. Engvall. 1999. Specific PCR identification and differentiation of the thermophilic Campylobacters, Campylobacter jejuni, C. coli, C. lari and C. upsaliensis. J. Clin. Microbiol. 37:3370-3373.

4.Giesendorf, B.A.J. and W.G.V. Quint. 1995. Detection and identification of Campylobacter spp. using the polymerase chain reaction. Cell. Mol. Biol. 41:625-638.

5.Gonzalez, I., K.A. Grant, P.T. Richardson, S.F. Park, and M.D. Collins. 1997. Specific identification of the enteropathogens Campylobacter jejuni and Campylobacter coli by using a PCR test based on the ceuE gene encoding a putative virulence determinant. J. Clin. Microbiol. 35:759-763.

6.Konkel, M.E., S.A. Gray, B.J. Kim, S.G. Garvis, and J. Yoon. 1999. Identification of the enteropathogens Campylobacter jejuni and Campylobacter coli based on the cadF virulence gene and its product. J. Clin. Microbiol. 37:510-517.

7.Mandrell, R.A. and M.R. Wachtel. 1999. Novel detection techniques for human pathogens that contaminate poultry. Curr. Opin. Biotechnol. 10:273-278.

8.Marshall, S.M., P.L. Melito, D.L. Woodward, W.M. Johnson, F.G. Rodgers, and M.R. Mulvey. 1999. Rapid identification of Campylobacter, Arcobacter and Helicobacter isolates by PCR-restriction fragment length polymorphism analysis of the $16 \mathrm{~S}$ rRNA gene. J. Clin. Microbiol. 37:4158-4160.

9.Metherell, L.A., J.M.J. Logan, and J. Stanley. 1999. PCR-enzyme-linked immunosorbent assay for detection and identification of
Campylobacter species: application to isolates and stool samples. J. Clin. Microbiol. 37:433435.

10.Oroskar, A.A., S.E. Rasmussen, H.N. Rasmussen, S.R. Rasmussen, B.M. Sullivan, and A. Johansson. 1996. Detection of immobilized amplicons by ELISA-like techniques. Clin. Chem. 42:1547-1555.

11.O'Sullivan, N.A., R. Fallon, C. Carroll, T. Smith, and M. Maher. 2000. Detection and differentiation of Campylobacter jejuni and Campylobacter coli in broiler chicken sam ples using a PCR/DNA probe membrane based colorimetric detection assay. Mol. Cell. Probes. 14:7-16.

12.Oyofo, B.A., S.A. Thornton, D.H Burr, T.J. Trust, O.R. Pavlovskis, and P. Guerry. 1992. Specific detection of Campylobacter jejuni and Campylobacter coli by using polymerase chain reaction. J. Clin. Microbiol. 30:2613-2619.

13.Rasmussen, H.N, J.E. Olsen, K. Jorgensen, and O.F. Rasmussen. 1996. Detection of Campylobacter jejuni and Camp. coli in chicken faecal samples by PCR. Lett. Appl. Microbiol. 23:363-366.

14.Roop, R.M., II, R.M. Smibert, J.L. Johnson, and N.R. Kreig. 1984. Differential characteristics of catalase-positive campylobacters correlated with DNA homology groups. Can. J. Microbiol. 30:938-951.

15.Saiki, R.K., S. Scharf, F. Faloona, K.B. Mullis, G.T. Horn, H.A. Erlich, and N. Arnheim. 1985 Enzymatic amplification of betaglobin genomic sequences and restriction site analysis for diagnosis of sickle cell anemia. Science 230:1350-1354.

16.Sambrook, J., E.F. Fritch, and T. Maniatis. 1989. Molecular Cloning: A Laboratory Manual. 2nd ed. CSH Laboratory Press, Cold Spring Harbor, NY.

17.Southern, E.M. 1975. Detection of specific sequences among DNA fragments separated by gel electrophoresis. J. Mol. Biol. 98:503.

18.Stern, N.J. 1992. Reservoirs for Campylobacter jejuni and approaches for intervention in poultry, p.49-60. In I. Nachamkin, M.J. Blaser, and L.S. Tompkins (Eds.). Campylobacter jejuni, Current Status and Future Trends. American Society for Microbiology, Washington DC.

Received 18 January 2000; accepted 31 August 2000.

Address correspondence to:

Majella Maher

DNA Diagnostics

National Diagnostics Centre

National University of Ireland

Galway, Ireland

e-mail:m.maher@nuigalway.ie 